\title{
INFLUENCE OF PALM-BASED FLUID SHORTENING ON THE PHYSICAL AND TEXTURAL PROPERTIES OF BISCUITS
}

\author{
NUR HAQIM ISMAIL*; MISKANDAR MAT SAHRI* and RAFIDAH ABD HAMID*
}

\begin{abstract}
The aim of this research was to evaluate the performance of palm-based fluid shortening on the quality of biscuits in comparison to the control biscuits produced with solid shortening and refined, bleached and deodourised (RBD) palm olein. Solid shortening had the highest content of saturated fatty acids mainly palmitic acid while RBD palm olein contains the highest amount of dominant unsaturated fatty acid which is oleic acid. The fatty acid composition showed an absence of trisaturated fatty acid in RBD palm olein. The hardness of the dough, biscuit dimensions and physical properties were evaluated. The dough of the biscuit containing solid shortening was the stiffest and highest in weight as compared to the dough of the biscuit containing fluid shortening and RBD palm olein. The values for diameter, length, thickness and spread ratio varied significantly $(P \leq 0.05)$. The study has demonstrated that the weight, thickness, spread ratio, moisture content and hardness of biscuits containing fluid shortening were insignificantly different $(P>0.05)$ with the biscuits containing solid shortening. Biscuits containing solid shortening had the highest lightness value $\left(L^{*}\right)$. Thus, the results indicated that the performance of the fluid shortening in biscuits is comparable with solid shortening.
\end{abstract}

Keywords: palm-based fluid shortening, biscuit, texture.

Date received: 23 October 2017; Sent for revision: 30 October 2017; Received in final form: 12 January 2018; Accepted: 2 February 2018.

\section{INTRODUCTION}

Biscuits are made from wheat flour, shortening, sugar, eggs, and other optional ingredients such as chocolate chips, dried fruits, nuts, and flavouring essence to enhance the taste and aroma of the biscuits. These ingredients are mixed together and churned, developing the gluten networking, referred to as dough. Fat plays a crucial role in developing the properties of the biscuits. The amount and type of fat incorporated in the dough have a great influence on the viscoelastic properties of the dough (Baltsavias et al., 1997) as well as the rheological properties of biscuit dough (Jissy and Leelavathi, 2007). Fat is also essential for preserving the quality

Malaysian Palm Oil Board, 6 Persiaran Institusi, Bandar Baru Bangi, 46000 Kajang, Selangor, Malaysia.

E-mail: nurhaqim.ismail@mpob.gov.my of the biscuit by contributing to the tenderness (O'Brien, 2003), promoting texture, mouthfeel and overall perception of lubricity of the product as a result of interactions with other ingredients (Giese, 1996; Stauffer, 1998).

In the production of biscuits, the solid fat content (SFC) in the fat impacts on the characterisation of the product at the temperature of biscuit preparation which is $25^{\circ} \mathrm{C}-30^{\circ} \mathrm{C}$. Basically, at least $15 \%-20 \%$ of fat in the solid state (Manley, 2000a) is required to obtain good quality biscuits. Shortenings with higher SFC do not have sufficient oil volume for satisfactory aeration. On the other hand, shortenings with lower SFC do not have the capacity to retain the air until mixing is complete. During mixing, the presence of some solid fat is crucial and the use of liquid oil will result in some detrimental effect in the handling characteristics of the dough (Jissy and Leelavathi, 2007). Several publications have shown 
that different types of fat used in making biscuits have a great impact on the quality of biscuits. It has been reported that the use of butter fat in biscuit impart its flavour and mouthfeel (Yanty et al., 2014). Goldstein and Seetharaman (2011) reported that all purpose shortening produced superior quality biscuits as compared to monoglyceride stabilised oil in water emulsion shortening. On the other hand, Sciarini et al. (2013) found that lauric-based shortening produced good quality biscuits.

Fluid shortening contains both liquid and solid phases. It comprises of moderately small (less than or equal to 15 micron) and stable beta crystalline phase in a fat network (Ghotra et al., 2002). Fluid shortening is convenient in the preparation of baked goods and bread-making processes (Gawrilow, 1980). The role of fluid shortenings in baking processes is comparable to the plastic shortenings, but fluid shortenings are much favoured for use in the commercial baking processes due to ease in handling, pumping, and metering (Ghotra et al., 2002). Plant-based shortenings especially palm oil is much preferred as an ingredient in biscuit formulation due to their functional properties as well as their cost-effectiveness (Yanty et al., 2014). However, the scientific data on the performance of fluid shortening in biscuits are scarcely found.

This study was done to ascertain the effects of palm-based fluid and solid shortenings and refined, bleached and deodourised (RBD) palm olein with varying SFC on the physical and textural properties of dough and biscuit.

\section{MATERIALS AND METHODS}

\section{Materials}

Commercially available wheat flour, sugar, eggs, baking powder, vanilla essence and RBD palm olein [iodine value (IV) 58] were procured from the local market. Palm oil $(\mathrm{IV}=52)$ and palm stearin $(\mathrm{IV}=33)$ were purchased from Mewah Oil Sdn Bhd and Sawit Raya Sdn Bhd, Selangor, Malaysia, respectively. Fluid shortening was prepared solely from palm oil according to the method as described by Che Man et al. (2009). Solid shortening from mixture of $20 \%$ of palm stearin and $80 \%$ of palm oil were produced at the Margarine Pilot Plant, Malaysian Palm Oil Board (MPOB), Malaysia.

\section{Solid Fat Content}

The SFC was measured by using pulse NMR (model NMS Minispec from Bruker, Rheinstentetten, Silberstreifen, Germany) and NMR tubes $(0.8 \mathrm{~cm}$ diameter and height of $2 \mathrm{~cm}$ ) for the direct $\mathrm{SFC}$ measurement. The solid samples were loaded carefully into the NMR tubes to avoid air gaps by using stainless steel piston. The sample tubes were cooled in a water-bath at temperatures of $5^{\circ} \mathrm{C}$, $10^{\circ} \mathrm{C}, 15^{\circ} \mathrm{C}, 20^{\circ} \mathrm{C}, 25^{\circ} \mathrm{C}, 30^{\circ} \mathrm{C}, 35^{\circ} \mathrm{C}, 40^{\circ} \mathrm{C}, 45^{\circ} \mathrm{C}$ and $50^{\circ} \mathrm{C}$ for $24 \mathrm{hr}$ following $30 \mathrm{~min}$ incubations at each temperature before SFC was measured (Jahaniaval et al., 2002; Miskandar et al., 2004; 2007).

\section{Fatty Acid Composition (FAC)}

The FAC was determined by dissolving $0.05 \mathrm{~g}$ of melted samples in $1 \mathrm{ml}$ hexane and reacting with 0.2 $\mathrm{ml}$ of $2 \mathrm{M}$ sodium methoxide solution (in anhydrous methanol). The mixture was vigorously shaken for 1 min with a vortex mixer. After the sedimentation of sodium glycerolate, $1 \mu \mathrm{m}$ of clear supernatant was injected into RTX 2330 fused silica capillary column $(60 \mathrm{~m} \times 0.25 \mathrm{~mm} \times 0.25 \mu)$ (Restex Corporation USA) and analysed using a Burker Gas Chromatography system Model 430-GC (Burker Daltonics, CA, USA) equipped with a flame ionisation detector (FID) and Galaxie Chromatography Data System. The detection and oven temperatures were set at $240^{\circ} \mathrm{C}$ and $190^{\circ} \mathrm{C}$, respectively. The column temperature was isothermal at $185^{\circ} \mathrm{C}$. Helium was used as the carrier gas with flow rate of $1 \mathrm{ml} \mathrm{min}^{-1}$. All chemicals and reagents used were of high performance liquid chromatography (HPLC) grade (Kanagaratnam et al., 2013).

\section{Triacylglycerol (TAG) Composition}

The TAG composition was performed using Ultra High Performance Liquid Chromatography (U-HPLC) system (1290 Infinity LC System, Agilent Technologies, USA) and Agilent 1260 Infinity RI detector (Agilent Technologies, USA). A Cortecs UPLC C18 column (2.1 mm x $150 \mathrm{~mm}$ length i.d; $1.6 \mu \mathrm{m}$ particle size) (Waters Corp., Milford, Massachusettes, USA) maintained at $30^{\circ} \mathrm{C}$ was used. The mobile phased used was a mixture of acetoneacetonitrile at ratio $63.5: 36.5(\mathrm{v} / \mathrm{v})$ at a flow rate of $0.25 \mathrm{ml} \mathrm{min}{ }^{-1}$. Samples $(1 \mathrm{ml})$ were solubilised in 1 $\mathrm{ml}$ of acetone and were filtered through a $0.2 \mu \mathrm{m}$ syringe filter (GHP, Waters). The chemicals and reagents used were HPLC grade. HPLC analysis was conducted in duplicate and data were recorded as percent areas.

\section{Preparation of Biscuits}

Biscuits were prepared using $400 \mathrm{~g}$ flour, 168 $\mathrm{g}$ fats, $180 \mathrm{~g}$ sugar, $50 \mathrm{~g}$ eggs, $3 \mathrm{~g}$ baking powder and $2.5 \mathrm{~g}$ vanilla essence. It started by mixing the fats with sugar for 2 min in a mixer (Hobart, US) at speed 1 to obtain homogenous cream. Then, vanilla essence and eggs were added and the mixture was continuously mixed at speed 2 for $30 \mathrm{~s}$. Then, the mixture was scrapped before finally adding the flour and baking powder and mixed at speed 1 for 
$1 \mathrm{~min}$. The biscuit dough was sheeted to a thickness of $3 \mathrm{~mm}$ and cut to a diameter of $41 \mathrm{~mm}$ using a standardised mould. The dough pieces were placed on a baking tray then baked at $180^{\circ} \mathrm{C}$ for $14 \mathrm{~min}$. After baking, the biscuits were allowed to cool for $30 \mathrm{~min}$. The biscuits were packed and sealed in polyethylene pouches and stored at room temperature $\left(25^{\circ} \mathrm{C}\right)$.

\section{Physical Characteristics of Dough and Biscuits}

The weight of the randomly selected biscuits were obtained by direct measurements before and after baking. The thickness, diameter and length of the biscuits were measured on a set of five biscuits for each recipe using a thickness meter. The spread ratio was determined using the formula: diameter/ thickness of biscuits (Zoulias et al., 2000). The moisture content of the biscuits was analysed using moisture analyser (AND model MX-5-, Japan). The surface colour of the biscuit was determined by using Chroma Meter CR-400 (Konica Minolta Sensing, Japan). The parameters determined were Commission on Illumination (CIE) colour values $L^{*}\left[L^{*}=0\right.$ (black) and $L^{*}=100$ (white)], a* $\left(-a^{*}=\right.$ greenness and $+a^{*}=$ redness $)$ and $b^{*}\left(-b^{*}\right.$ $=$ blueness and $+b^{*}=$ yellowness).

\section{Texture Profile Analysis (TPA) of Dough and Biscuits}

The dough hardness was determined according to Pareyt et al. (2008) with modification in four replications using the texture analyser (model TA.XT plus, Stable Micro System, England) equipped with a $5 \mathrm{~kg}$ load cell in the measure force in compression mode with a cylindrical probe $(50 \mathrm{~mm}$ diameter). Pre- and post-test speeds were $2.0 \mathrm{~mm} \mathrm{~s}^{-1}$, while test speed was $1.0 \mathrm{~mm} \mathrm{~s}^{-1}$. The hardness of the biscuits was evaluated using a TA.XT plus texture analyser with a $50 \mathrm{~mm}$ aluminium probe by penetration mode. A pre-test speed of $1 \mathrm{~mm} \mathrm{~s}^{-1}$, test speed of 1 $\mathrm{mm} \mathrm{s}^{-1}$ and post-test speed of $2 \mathrm{~mm} \mathrm{~s}^{-1}$. Eight biscuits were measured for each sample to determine the maximum peak force which is the hardness.

\section{Statistical Analysis}

Results were analysed with Minitab version 16.0 (Pennsylvania, USA) using one-way analyses of variance (ANOVA). Significance differences $(\mathrm{P} \leq 0.05)$ among the samples were analysed using the Tukey's Post-Hoc test.

\section{RESULTS AND DISCUSSION}

\section{SFC Profiles of the Shortening}

The SFC profiles of the solid shortening, fluid shortening and RBD palm olein are shown in Figure 1. The RBD palm olein contains $31.94 \%$ of $\mathrm{SFC}$ at $5^{\circ} \mathrm{C}$ and is completely melted at $20^{\circ} \mathrm{C}$. This indicates that the RBD palm olein is liquid at temperatures more than $20^{\circ} \mathrm{C}$. In contrast, solid and fluid shortenings contain $70.13 \%$ and $66.27 \%$ SFC, respectively. However, the SFC of solid and fluid shortenings decreased gradually at $25^{\circ} \mathrm{C}$ to $25.28 \%$ and $15.53 \%$, respectively. The SFC of solid and fluid shortenings are further decreased to $18.07 \%$ and $9.97 \%$,

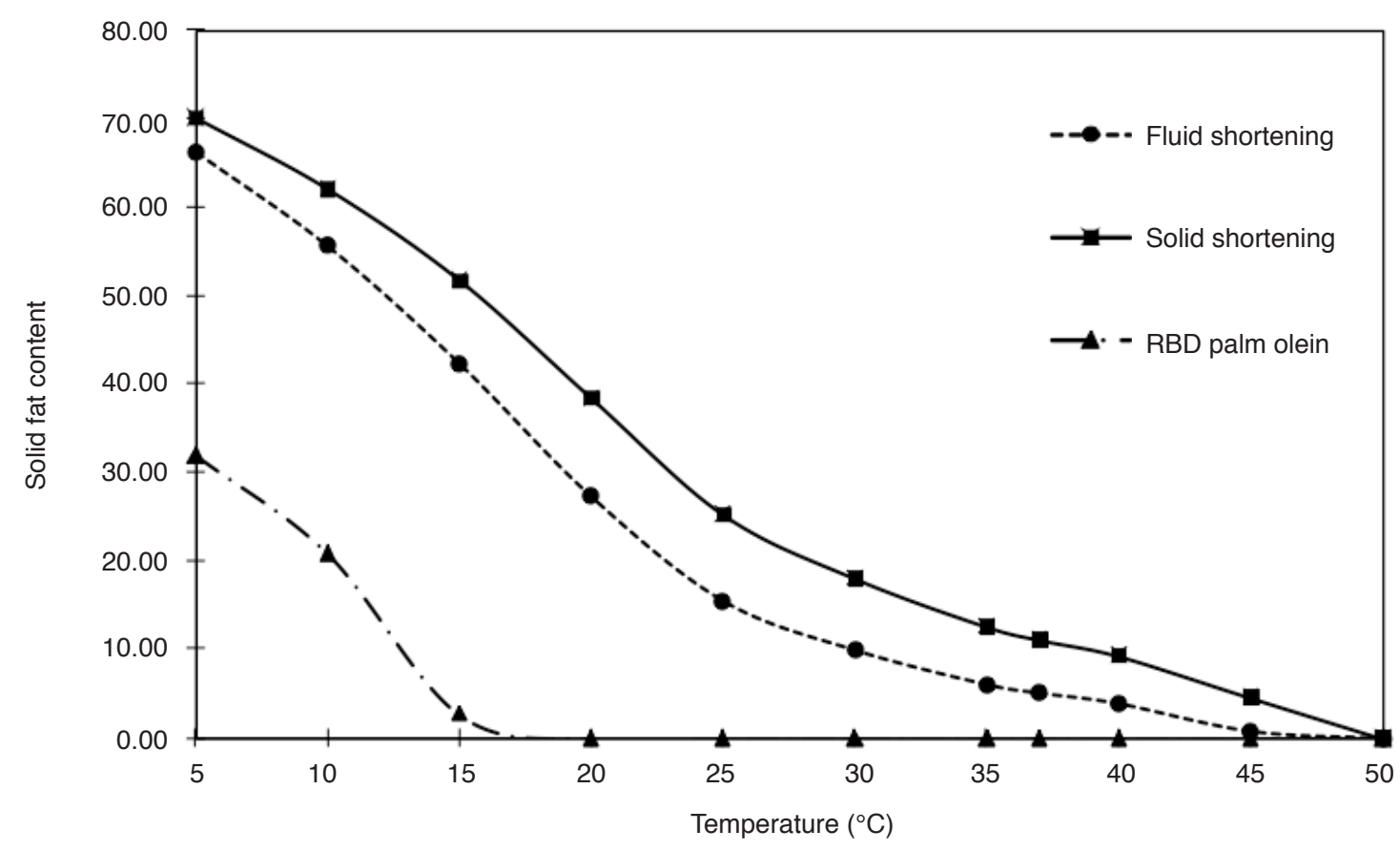

Figure 1. Solid fat content (SFC) of solid shortening, fluid shortening and refined, bleached and deodourised $(R B D)$ palm olein $(n=3)$. 
respectively, at $30^{\circ} \mathrm{C}$. Stauffer (2005) suggested that, in order to have a good machinability properties of biscuit dough, it is crucial to maintain the correct balance between the solid and liquid phase in the shortening. In the bakeries, at the average temperature of $25^{\circ} \mathrm{C}-30^{\circ} \mathrm{C}$, which are the working temperature, shortening will be in the plastic/semisolid form, with an optimum consistency for baking activities. In this regard, the SFC was the highest for solid shortening, followed by fluid shortening and RBD palm olein at working temperature. Basically, at least $15 \%-20 \%$ of fat in solid state (Manley, 2000a) is required to obtain good quality biscuits. Fluid and solid shortenings have $15.53 \%$ to $9.97 \%$ and $25.28 \%$ to $18.07 \%$, respectively of SFC at $25^{\circ} \mathrm{C}-30^{\circ} \mathrm{C}$ at dough preparation temperature which falls in the recommended SFC for biscuit fat.

\section{Shortening Composition}

FAC of solid shortening, fluid shortening and RBD palm olein are tabulated in Table 1. The fatty acids in solid shortening, fluid shortening and RBD palm olein were mainly the palmitic acid (C16:0) and the dominant unsaturated fatty acids were oleic (C18:1) and linoleic acid (C18:2). There were other fatty acids present but in small quantity. Solid shortening contains the highest palmitic acid which is $49.59 \%$ compared to $46.23 \%$ and $38.26 \%$ in fluid shortening and RBD palm olein, respectively. Whereas for the dominant unsaturated fatty acid, oleic acid, was the highest in RBD palm olein which is $42.82 \%$ compared to $37.77 \%$ and $35.14 \%$ in fluid shortening and solid shortening, respectively. RBD palm olein was found to have the highest monounsaturated and polyunsaturated fatty acids but the lowest amount of saturated fatty acids as compared to solid shortening and fluid shortening.

The relative percentage of TAG molecular species is shown in Table 1. There were 15 TAG detected in solid shortening, fluid shortening and RBD palm olein, namely OLL, PLL, MLP, OLO, PLO, PLP, MPP, OOO, POO, POP, PPP, SOO, POS, PPS and SOS, by which $\mathrm{M}, \mathrm{L}, \mathrm{O}, \mathrm{P}$ and $\mathrm{S}$ exhibit myristic, linoleic, oleic,

TABLE 1. FATTY ACIDS (FAC) AND TRIACYLGLYCEROL (TAG) COMPOSITION (\%) IN SOLID SHORTENING, FLUID SHORTENING AND RBD PALM OLEIN

\begin{tabular}{|c|c|c|c|}
\hline & Solid shortening & Fluid shortening & RBD palm olein \\
\hline \multicolumn{4}{|c|}{ Fatty acids } \\
\hline C12:0 & $0.18 \pm 0.01^{b}$ & $0.19 \pm 0.00^{b}$ & $0.55 \pm 0.00^{\mathrm{a}}$ \\
\hline C14:0 & $1.07 \pm 0.00^{\mathrm{b}}$ & $1.04 \pm 0.00^{c}$ & $1.09 \pm 0.00^{\mathrm{a}}$ \\
\hline $\mathrm{C} 16: 0$ & $49.59 \pm 0.01^{\mathrm{a}}$ & $46.23 \pm 0.00^{b}$ & $38.26 \pm 0.04^{c}$ \\
\hline C16:1 & $0.17 \pm 0.02^{\mathrm{a}}$ & $0.20 \pm 0.00^{\mathrm{a}}$ & $0.21 \pm 0.04^{\mathrm{a}}$ \\
\hline C18:0 & $4.87 \pm 0.01^{\mathrm{a}}$ & $4.69 \pm 0.00^{b}$ & $4.34 \pm 0.00^{c}$ \\
\hline C18:1 & $35.14 \pm 0.02^{c}$ & $37.77 \pm 0.03^{b}$ & $42.82 \pm 0.03^{a}$ \\
\hline C18:2 & $8.36 \pm 0.01^{\mathrm{c}}$ & $9.24 \pm 0.01^{\mathrm{b}}$ & $11.95 \pm 0.00^{\mathrm{a}}$ \\
\hline C18:3 & $0.18 \pm 0.00^{c}$ & $0.21 \pm 0.00^{\mathrm{b}}$ & $0.33 \pm 0.00^{\mathrm{a}}$ \\
\hline C20:0 & $0.32 \pm 0.00^{\mathrm{a}}$ & $0.33 \pm 0.05^{\mathrm{a}}$ & $0.37 \pm 0.05^{\mathrm{a}}$ \\
\hline SFA & $56.04 \pm 0.01^{\mathrm{a}}$ & $52.48 \pm 0.03^{b}$ & $44.62 \pm 0.01^{\mathrm{c}}$ \\
\hline MUFA & $35.31 \pm 0.01^{c}$ & $37.98 \pm 0.01^{b}$ & $43.03 \pm 0.00^{\mathrm{a}}$ \\
\hline PUFA & $8.55 \pm 0.00^{c}$ & $9.45 \pm 0.04^{\mathrm{b}}$ & $12.27 \pm 0.01^{\mathrm{a}}$ \\
\hline \multicolumn{4}{|l|}{$\mathrm{TAG}^{*}$} \\
\hline OLL & $0.24 \pm 0.01^{\mathrm{c}}$ & $0.28 \pm 0.01^{b}$ & $0.51 \pm 0.00^{\mathrm{a}}$ \\
\hline PLL & $1.10 \pm 0.01^{\mathrm{c}}$ & $1.26 \pm 0.03^{b}$ & $1.93 \pm 0.02^{\mathrm{a}}$ \\
\hline MLP & $0.24 \pm 0.04^{\mathrm{a}}$ & $0.32 \pm 0.11^{\mathrm{a}}$ & $0.24 \pm 0.02^{\mathrm{a}}$ \\
\hline OLO & $1.02 \pm 0.02^{\mathrm{c}}$ & $1.17 \pm 0.02^{\mathrm{b}}$ & $1.54 \pm 0.02^{\mathrm{a}}$ \\
\hline PLO & $7.98 \pm 0.13^{c}$ & $9.04 \pm 0.12^{\mathrm{b}}$ & $10.94 \pm 0.07^{\mathrm{a}}$ \\
\hline PLP & $7.07 \pm 0.03^{c}$ & $7.59 \pm 0.08^{b}$ & $8.96 \pm 0.03^{a}$ \\
\hline MPP & $0.93 \pm 0.04^{\mathrm{a}}$ & $0.63 \pm 0.01^{b}$ & - \\
\hline OOO & $3.91 \pm 0.10^{\mathrm{b}}$ & $4.26 \pm 0.37^{b}$ & $5.22 \pm 0.08^{\mathrm{a}}$ \\
\hline $\mathrm{POO}$ & $23.96 \pm 0.49^{c}$ & $27.06 \pm 0.16^{b}$ & $33.66 \pm 0.22^{\mathrm{a}}$ \\
\hline POP & $31.75 \pm 0.07^{a}$ & $31.88 \pm 0.15^{\mathrm{a}}$ & $28.04 \pm 0.08^{b}$ \\
\hline PPP & $11.17 \pm 0.56^{\mathrm{a}}$ & $6.53 \pm 0.07^{b}$ & - \\
\hline $\mathrm{SOO}$ & $2.48 \pm 0.06^{c}$ & $2.77 \pm 0.08^{b}$ & $3.62 \pm 0.17^{\mathrm{a}}$ \\
\hline POS & $5.34 \pm 0.04^{\mathrm{a}}$ & $5.32 \pm 0.09^{a}$ & $4.72 \pm 0.15^{\mathrm{b}}$ \\
\hline PPS & $2.19 \pm 0.14^{\mathrm{a}}$ & $1.20 \pm 0.06^{\mathrm{b}}$ & - \\
\hline SOS & $0.59 \pm 0.03^{\mathrm{a}}$ & $0.65 \pm 0.02^{\mathrm{a}}$ & $0.60 \pm 0.04^{\mathrm{a}}$ \\
\hline
\end{tabular}

Note: ${ }^{a}$ Data are mean values of duplicates. Coefficient of variation was within $5 \%$.

Different letters for each row indicate significant difference $(P \leq 0.05)$ between the samples.

SFA - saturated fatty acid; MUFA - monounsaturated fatty acid; PUFA - polyunsaturated fatty acid.

$\mathrm{M}$ - myristic; L- linoleic; O - oleic; P - palmitic, and S - stearic. 
TABLE 2. WEIGHT AND HARDNESS OF THE DOUGH

\begin{tabular}{lcc}
\hline Sample & \multicolumn{2}{c}{ Dough } \\
\cline { 2 - 3 } & Weight $(\mathrm{g})$ & Hardness $(\mathrm{g})$ \\
\hline SS & $6.83 \pm 0.21^{\mathrm{a}}$ & $492.48 \pm 9.79^{\mathrm{a}}$ \\
FS & $7.40 \pm 0.10^{\mathrm{b}}$ & $364.71 \pm 19.22^{\mathrm{b}}$ \\
POo & $7.29 \pm 0.10^{\mathrm{b}}$ & $361.83 \pm 11.99^{\mathrm{b}}$ \\
\hline
\end{tabular}

Note: Different letters for each column indicate significant differences $(\mathrm{P} \leq 0.05)$ between the samples.

SS - solid shortening; FS - fluid shortening; POo - refined, bleached and deodourised palm olein.

palmitic ans stearic, respectively. These TAG were categorised as SSU (disaturated-monounsaturated), SUU (monosaturated-diunsaturated), UUU (triunsaturated) and SSS (trisaturated). SSU consists of MLP, PLP, POP, POS and SOS. SUU consists of PLL, PLO, POO and SOO. UUU consists of OLL, OLO and OOO. SSS consists of MPP, PPP and PPS. Solid and fluid shortenings and RBD palm olein are predominantly consisted of SSU, SUU and UUU type TAG. Absence of SSS is noted in RBD palm olein sample. RBD palm olein contains the highest amount of unsaturated fatty acids compared to solid and fluid shortening. This explains why RBD palm olein is liquid at temperatures higher than $20^{\circ} \mathrm{C}$ compared to solid and fluid shortenings. Solid and fluid shortenings are solid and semisolid at working temperature as they contain high palmitic acid (16:0) as compared to RBD palm olein. Increasing the concentration of palm stearin in the shortenings was found to decrease the TAG, such as PLO, POO and POP. Solid shortening was found to have the highest trisaturated TAG such as MPP, PPP and PPS than fluid shortening.

\section{Dough Properties}

The dough of biscuits produced using solid shortening was significantly lower in weight as compared to the one processed using fluid shortening and RBD palm olein (Table 2). However, the result of the hardness values by texture analyser was in contrast with the weight values where the hardness of the dough containing solid shortening was significantly higher than the other samples (Table 2). The dough became harder and more crumbly. It has been reported that the highest value of hardness was observed in the dough made with the highest SFC contents (Sciarini et al., 2013). This suggests that the findings are aligned with Jissy and Leelavathi (2007) that the dough containing oil is generally softer as it is more cohesive and viscous. Adversely, the dough containing solid shortening was harder due to higher SFC in the shortening. This explained that there is a competition between the aqueous phase and the fat on the surface of the flour which occurs during the dough mixing process. Gluten is developed when water or sugar solution interacted with the protein in the flour, resulting in a cohesive and extensible network. The existence of fat will coat the flour particles and disrupt the formation of gluten network making the biscuits to reduce in hardness and shorter (Manley, 2000b).

\section{Biscuit Properties}

The weight of biscuit samples was not significantly difference $(\mathrm{P}>0.05)$ (Table 3$)$. However, the diameter, length, thickness and spread ratio among the samples showed significant difference. Biscuits containing solid shortening had the highest diameter and length values compared to the biscuits containing fluid shortening and RBD palm olein. However, the latter showed no significant difference in diameter and length (Table 3). Diameter (spreadability) of biscuits is one of the important parameter in determining the quality of the biscuit (Hadnadev et al., 2015). The regularity of the biscuit diameter will assist in better and economical packaging size while an irregular ones will cause a lot of products being rejected.

During baking, the dough starts to spread due to the disintegration of sucrose and melting of fat. This phenomenon continues during the baking time until the structure is completely set due to the increase in dough viscosity (Doescher et al., 1987). The spreadness and thickness are related to the amount of fat content in biscuits (Manohar and Rao, 1999). It has been reported that a higher biscuit thickness

TABLE 3. PHYSICAL PROPERTIES OF BISCUITS

\begin{tabular}{|c|c|c|c|c|c|c|c|c|c|c|}
\hline \multirow[t]{2}{*}{ Sample } & \multirow{2}{*}{$\begin{array}{l}\text { Weight } \\
\text { (g) }\end{array}$} & \multirow{2}{*}{$\begin{array}{l}\text { Diameter } \\
\text { (mm) }\end{array}$} & \multirow{2}{*}{$\begin{array}{l}\text { Length } \\
(\mathrm{mm})\end{array}$} & \multirow{2}{*}{$\begin{array}{c}\text { Thickness } \\
\text { (mm) }\end{array}$} & \multirow{2}{*}{$\begin{array}{l}\text { Spread } \\
\text { ratio }\end{array}$} & \multirow{2}{*}{$\begin{array}{c}\text { Moisture } \\
\text { content }(\%)\end{array}$} & \multicolumn{3}{|c|}{ Colour } & \multirow{2}{*}{$\begin{array}{c}\text { Hardness } \\
\text { (g) }\end{array}$} \\
\hline & & & & & & & $\mathrm{L}^{*}$ & $a^{x}$ & $\mathrm{~b}^{\star}$ & \\
\hline SS & $\begin{array}{l}6.19 \pm \\
0.17^{\mathrm{a}}\end{array}$ & $\begin{array}{r}4.58 \pm \\
0.05^{\mathrm{a}}\end{array}$ & $\begin{array}{c}4.55 \pm \\
0.01^{\mathrm{a}}\end{array}$ & $\begin{array}{l}0.69 \pm \\
0.01^{\text {ab }}\end{array}$ & $\begin{array}{l}6.61 \pm \\
0.14^{\mathrm{ab}}\end{array}$ & $\begin{array}{c}2.42 \pm \\
0.25^{\mathrm{a}}\end{array}$ & $\begin{array}{c}78.59 \pm \\
0.74^{\mathrm{a}}\end{array}$ & $\begin{array}{c}-0.06 \pm \\
0.11^{\mathrm{a}}\end{array}$ & $\begin{array}{c}23.54 \pm \\
0.47^{\mathrm{a}}\end{array}$ & $\begin{array}{c}2088.0 \pm \\
152.3^{\mathrm{b}}\end{array}$ \\
\hline FS & $\begin{array}{c}6.24 \pm \\
0.11^{\mathrm{a}}\end{array}$ & $\begin{array}{r}4.48 \pm \\
0.02^{\mathrm{b}}\end{array}$ & $\begin{array}{l}4.44 \pm \\
0.04^{\mathrm{b}}\end{array}$ & $\begin{array}{c}0.79 \pm \\
0.15^{\mathrm{a}}\end{array}$ & $\begin{array}{c}5.84 \pm \\
1.19^{\mathrm{b}}\end{array}$ & $\begin{array}{r}2.36 \pm \\
0.13^{\mathrm{a}}\end{array}$ & $\begin{array}{c}72.85 \pm \\
1.82^{\mathrm{b}}\end{array}$ & $\begin{array}{c}-0.06 \pm \\
0.09^{a}\end{array}$ & $\begin{array}{c}24.00 \pm \\
1.47^{\mathrm{a}}\end{array}$ & $\begin{array}{c}2258.3 \pm \\
125.1^{\mathrm{b}}\end{array}$ \\
\hline POo & $\begin{array}{c}6.07 \pm \\
0.06^{\mathrm{a}}\end{array}$ & $\begin{array}{l}4.43 \pm \\
0.02^{\mathrm{b}}\end{array}$ & $\begin{array}{c}4.41 \pm \\
0.01^{\mathrm{b}}\end{array}$ & $\begin{array}{c}0.53 \pm \\
0.01^{\mathrm{b}}\end{array}$ & $\begin{array}{l}8.30 \pm \\
0.16^{\mathrm{a}}\end{array}$ & $\begin{array}{c}2.75 \pm \\
0.08^{\mathrm{a}}\end{array}$ & $\begin{array}{c}75.26 \pm \\
0.26^{\mathrm{b}}\end{array}$ & $\begin{array}{c}-0.00 \pm \\
0.15^{\mathrm{a}}\end{array}$ & $\begin{array}{c}24.02 \pm \\
0.20^{\mathrm{a}}\end{array}$ & $\begin{array}{c}2770.9 \pm \\
24.4^{\mathrm{a}}\end{array}$ \\
\hline
\end{tabular}

Note: Different letters for each column indicate significant differences $(\mathrm{P} \leq 0.05)$ between the samples.

SS - solid shortening; FS - fluid shortening; POo - refined, bleached and deodourised palm olein. 
was associated with lower SFC. Usually fats with lower SFC produce dough with lower consistencies that will be easily expanded during baking and gas release (Sciarini et al., 2013). However, Table 3 shows contradicting results in the biscuit diameter. Biscuits with the highest SFC showed the highest thickness. This scenario was associated with the lower spreading of these biscuits during baking. Fluid shortening and solid shortenings had good leavening which produced biscuits with double the original height. Biscuits containing fluid shortening were the thickest, but was not significantly thicker than solid shortening. Biscuits containing RBD palm olein had the lowest thickness value. However, the trend was contradictory in the values of spread ratio. The values of spread ratio increases with the decrease values of diameter and thickness of the biscuit (Table 3).

Biscuits containing RBD palm olein had the highest spread ratio than the others. That might be because there is oiling out from the dough. These results are in agreement with the findings by Jissy and Leelavathi (2007). Their studies also proved that the biscuits containing oil spread earlier than the others and continue to spread for a longer time. However, there was no significant difference in the moisture content of the biscuits.

The surface colour of the biscuits showed significant difference on $L^{*}$ value. Biscuits containing solid shortening had the highest $\mathrm{L}^{*}$ value which was 78.59. Shibukawa et al. (1989) explained that the difference in the $L^{*}$ value was reported as a function of the temperature of the biscuit surface. The differences observed in sample $\mathrm{L}^{*}$ values seen in this study may be associated to the treatment of the shortening and their inherent heat transfer coefficients as the other parameters such as temperature, air velocity, and humidity were constant throughout baking for all cookie samples (Goldstein and Seetharaman, 2011).

\section{Biscuits Texture Evaluation}

The textural characteristic is another important criteria in evaluating the quality of biscuits. It is noted that the hardness value increases in biscuits with low SFC (Table 3). Biscuits containing RBD palm olein possess the highest hardness values compared to the other biscuits due to the poor air entrapment during creaming as explained by Jissy and Leelavathi (2007). Kamel (1994) claimed that the hard texture of biscuits made from liquid oil is due to the fact that the liquid oil is not able to retain the air in the system although there is an enourmous amount of air being integrated in the liquid oil.

The biscuit break strength increased when the fat levels in the recipe were reduced. This scenario was linked to more gluten cross-linking in the biscuits (Pareyt et al., 2010). In making good biscuits, plasticity in fats is crucial for the creaming process as this will entrap and retain ample volumes of air that contributes to the leavening effect. On the other hand, typical liquid oils such as RBD palm olein are diffused upon mixing through out the dough making them less effective in their shortening and aerating actions (Hartnett and Thalheimer, 1979; Jissy and Leelavathi, 2007).

\section{CONCLUSION}

The study has demonstrated that the weight, thickness, spread ratio, moisture content and hardness of biscuits containing fluid shortening were not significantly different $(\mathrm{P}>0.05)$ to the biscuits containing solid shortening. The SFC of the shortening significantly influenced the hardness of the biscuits where low SFC shortening has resulted in high hardness values. Thus, it is concluded that the performance of the fluid shortening in biscuits is comparable to the solid shortening.

\section{ACKNOWLEDGEMENT}

The authors would like to thank the Director-General of MPOB for permission to publish this article.

\section{REFERENCES}

BALTSAVIAS, A; JURGENS, A and VANVLIET, T (1997). Rheological properties of short doughs at small deformation. J. Cereal Sci., 26(3): 289-300.

CHE MAN, Y B; MISKANDAR, M S; ABDUL RAHMAN, R; NOR AINI, I and YUSOFF, M S A (2009). Monitoring crystal development in palm oil-based fluid shortening production by FT-IR spectroscopy. J. Food Process Pres., 34: 68-82.

DOESCHER, L C; HOSENEY, R C and MILLIKEN, G A (1987). A mechanism for cookie dough setting. Cereal Chem., 64(3): 158-163.

GAWRILOW, I (1980). Fluid shortening. Strongsville, Ohio. US patent. US 4234606 A.

GHOTRA, B S; DYAL, S D; SURESH, S and NARINE, $S$ (2002). Lipid shortenings: a review. Food Res Int., 35: 1015-1048.

GIESE, J (1996). Fats and fat replacers, balancing the health benefits. Food Technology, 50: 76-78.

GOLDSTEIN, A and SEETHARAMAN, K (2011). Effect of a novel monoglyceride stabilized oil in water emulsion shortening on cookie properties. Food Research International, 44: 1476-1481. 
HADNAĐEV, T D; HADNAĐEV, M; POJIĆ, M; RAKITA, S and KRSTONOŠIĆ, V (2015). Functionality of OSA starch stabilized emulsions as fat replacers in cookies. J. Food Eng., 167: 133-138.

HARTNETT, D I and THALHEIMER, W G (1979). Use of oil in baked products - Part I: Background and bread. J. Amer. Oil Chem. Soc., 56: 944-947.

JAHANIAVAL, F; KAKUDA, Y and ABRAHAM, V (2002). Oil-binding capacity of plastic fats: effects of intermediate melting point TAG. J. Amer. Oil Chem. Soc., 79: 389-394.

JISSY, J and LEELAVATHI, K (2007). Effect of fattype on cookie dough and cookie quality. J. Food Eng., 79: 299-305.

KAMEL, B S (1994). Creaming, emulsions, and emulsifiers. The Science of Cookie and Cracker Production (Hamed, F Faridi ed.). New York: Chaman \& Hall.

KANAGARATNAM, S; ENAMUL HOQUE, M; MISKANDAR, $M S$ and ANDREW SPOWAGE, A (2013). Investigating the effect of deforming temperature on the oil-binding capacity of palm oil based shortening. J. Food Eng., 118: 90-99.

MANLEY, D (2000a). Short dough biscuits. Technology of Biscuits, Crackers and Cookies. (Manley, D ed.). Boca Raton, USA: CRC Press. p. 274-284.

MANLEY, D (2000b). Fats and oils. Technology of Biscuits, Crackers and Cookies. (Manley, D ed.). Boca Raton, USA: CRC Press. p. 130-150.

MANOHAR, R S and RAO, P H (1999). Effect of emulsifiers, fat level and type on the rheological characteristics of biscuit dough and quality of biscuits. J. Sci Food Agric., 79(10): 1223-1231.

MISKANDAR, M S; CHE MAN, Y B; ABDUL RAHMAN, R; NOR AINI, I and YUSOFF, M S A
(2007). Effects of emulsifiers on crystal behavior of palm oil blends on slow crystallization. J. Food Lipids, 14: 1-18.

MISKANDAR, M S; CHE MAN, Y B; ABDUL RAHMAN, R; NOR AINI, I and YUSOFF, M S A (2004). Palm oil crystallization: Effects of cooling time and oil content. J. Food Lipids, 11: 190-207.

O'BRIEN, R D (2003). Fats and Oils: Formulating and Processing for Applications. Boca Raton, USA: CRC Press,.

PAREYT, B; BRIJS, K and DELCOUR, J A (2010). Impact of fat on dough and cookie properties of sugar-snap cookies. Cereal Chem., 87(3): 226-230.

SCIARINI, LS; VAN BOCKSTAEL, F; NUSANTORO, B; PÉREZ, G T and DEWETTINCK, K (2013). Properties of sugar-snap cookies as influenced by lauric-based shortenings. J. Cereal Sci., 58: 234-240.

SHIBUKAWA, S; SUGIYAMA, $\mathrm{K}$ and YANO, $\mathrm{T}$ (1989). Effects of heat-transfer by radiation and convection on browning of cookies at baking. J. Food Science, 54(3): 621-624.

STAUFFER, C E (2005). Fats and oils in bakery products. Bailey's Industrial Oil and Fat Products (Shahidi, F ed.). Vol 4. John Wiley \& Sons, New York Inc. p. 207-216.

STAUFFER, C E (1998). Fats and oils in bakery products. Cereal Food World, 43: 120-126.

YANTY, N A M; MARIKKAR, J M N and ABDULKARIM, S M (2014). Determination of types of fat ingredient in some commercial biscuit formulations. Int Food Res J., 21(1): 277-282.

ZOULIAS, E I; PIKNIS, S and OREOPOULOU, V (2000). Effect of sugar replacement by polyols and Acesulfane-K on properties of low fat cookies. J. Sci Food Agric., 80(14): 2049-2056. 